\title{
Systems Thinking for the Middle Manager and Aspiring Leader in Public Health
}

\author{
W. Michael Reid1, Claudia Jennifer Dold² \\ ${ }^{1}$ Center for Leadership in Public Health Practice, College of Public Health, University of South Florida, Tampa, Florida, USA \\ ${ }^{2}$ Retired Research Librarian for Health Sciences, University of South Florida, Tampa, Florida, USA \\ Email:mreid@usf.edu,claudia.dold@gmail.com
}

How to cite this paper: Reid, W. M., \& Dold, C. J. (2020). Systems Thinking for the Middle Manager and Aspiring Leader in Public Health. Open Journal of Leadership, 9, 84-95.

https://doi.org/10.4236/oj1.2020.91006

Received: February 27, 2020

Accepted: March 28, 2020

Published: March 31, 2020

Copyright (c) 2020 by author(s) and Scientific Research Publishing Inc. This work is licensed under the Creative Commons Attribution International License (CC BY 4.0).

http://creativecommons.org/licenses/by/4.0/

(c) (i) Open Access

\begin{abstract}
The staff of a state public health leadership institute used a national leadership competency set as guidance for its curriculum. An important competency of that and several other national competency sets is systems thinking. Efforts to provide useful training in systems thinking were only partially successful. Literature searches revealed only one successful application in practice, even though surveys find that systems thinking continues to be a critical training need. During its final year, the staff of the institute developed a framework for a personal system thinking approach, which was favorably received by institute participants. The great majority of the participants in the institute were middle managers who were expected to develop their leadership skills and advance in their careers. This paper presents a refined version of the systems thinking framework. Among the advantages, it provides are: it requires no expenditure other than time, it requires no consultants, it can be tailored to the needs of any worker, it can be revisited as often as desirable, it recognizes that conflict and competition are ever-present in organizations and agencies, and it a can provide a roadmap for personal leadership action.
\end{abstract}

\section{Keywords}

Systems Thinking, Leadership, Competencies, Workforce Development

\section{Introduction}

The idea of a system, if not the term itself, has been a way of thinking about human relationships at least since Greek philosophers studied the polis (Aristotle, 1962: pp. 289-295). For public health, it seems clear that Winslow (1920) was thinking in terms of systems, although he did not use the term in his seminal article a century ago. System now is an ubiquitous word in writings on public 
health. Hardly an article or book in the field avoids using "the public health system" or public health systems. The Institute of Medicine (1988: p. 73) at one point defined the public health system (in terms of public and private organizations) and subsequently reported on the differing public health systems in several states (p. 81). It is a term and concept viewed with great favor (Lammers \& Vandna, 1997) and deeply embedded in the culture and ideology of public health officials and scholars in the United States. Competency in systems thinking is considered an essential aspect of leadership.

The Institute of Medicine Report did much to stimulate the use of the term "public health system" in the professional literature and federal, state, and association policy documents. A major impetus to the use of systems thinking by practitioners was the consequence of one of the Institute findings "there was little specific focus in public health education on leadership development" (p. 6). The report recommended adding leadership to curricula in schools of public health. The Centers for Disease Control and Prevention soon established grants to create public health leadership institutes at the national, regional, and state levels primarily in schools of public health. These then created a formal network of such institutes. The major conceptual work of the leadership institute network was the creation of a competency set that contained a prominent place for systems thinking (Wright et al., 2000). This competency framework became the basis for the institutes' training programs reaching thousands of public health practitioners and academics. Systems thinking subsequently became an integral part of several other public health competency frameworks, accreditation standards, certification requirements, and curricula in schools of public health (Reid \& Dold, 2016).

Over the past 25 years or so, significant efforts have been made to strengthen the public health workforce through increased training. This training has often been structured around the competencies noted above (including systems thinking). However, one of the findings of our recent literature search is that there is apparently a continuing strong need for improving systems thinking skills in the public health workforce. Numerous studies and commentary consistently identify systems thinking as a priority for further training (Angeloni, Bialek, Petros, \& Fagen, 2019; Brunton \& Smedley, 2019). Despite the training efforts of public health organizations, there is a need for more and/or better training in systems thinking skills. In addition, given the workforce turnover in public health agencies, there will be an ongoing need for training, and it is likely that the resources available for such training will be increasingly scarce.

\section{Systems Thinking in a State Level Leadership Institute Curriculum}

In view of this continued and strong need for systems thinking training, the experience of a state level public health leadership institute may be helpful for other public health organizations that wish to strengthen their members' systems 
thinking skills. The experience included many measures that were marginally useful and one approach that held considerable promise for structuring a person's systems thinking. The lead author of this article was director of such an institute and a member of the network of institutes. I was part of the group that drafted the competency framework. My staff and I used the framework for our curricula annually, with systems thinking being an integral element (as it was for the approximately 30 other institutes at the national, state, and regional levels). Most of the 400 or so scholars who participated in the institute were mid-level managers, working either in the state health office or one of the state's county health departments. They were recommended for participation because of their leadership potential for their agencies. We considered their place in the bureaucracy and their aspirations for leadership as an important factor in shaping the curriculum.

\subsection{Strategies Adopted to Integrate Systems Thinking into Curriculum}

Over the course of the institute's life, we assigned books and readings that emphasized systems thinking (Senge, 1990; Senge et al., 1994), employed expert consultants and workshop trainers, made field assignments based on the reading and workshops, and encouraged the participants to use systems thinking in their year-long projects.

In addition, we looked for guidance and materials that might be helpful to us in designing the systems thinking portion of the institute curriculum. Thus, some of our staff-led workshops relied on readings and other materials that defined and described a public health system. We hoped these would help the scholars in conceptualizing the public health system. We found a fairly wide variety of statements defining the public health system. For example, at the time, the National Public Health Performance Standards Program (NPHPSP) defined public health systems as "the collection of public, private and voluntary entities, as well as individuals and informal associations, that contribute to the public's health in a jurisdiction" (Lenaway et al., 2006: p. 411). Others added factors such as We also found definitions broader in scope, taking in many organizations and including such factors as "a complex web of norms, values and collectivities of the society at large". This broad environment includes partners and relationships that are vital components of the system (Meyer, Davis, \& Mays, 2012).

Some scholars wrote about systems thinking in abstract terms of structures and processes among or within public health agencies and other organizations (Williams, 2015). Others followed the approach of the field of health services research, studying the organization, financing, and delivery of public health services generally focusing on formal public health agencies (Mays, Halverson, \& Scutchfield, 2003). These approaches were naturally chosen by scholars and researchers who were looking at public health systems from an "outside" perspective-that of the scientific observer. Other scholars recognized the importance of 
communication among the members of a system (Hoehner et al., 2015). This implies a personal and thus a distinctive relationship between members of a system, as opposed to the objective approach of a research study. This point eventually became an important perspective in our training approach.

We concluded that these kinds of descriptions or definitions were helpful to the scholar in the sense of suggesting ways of looking at public health systems but were not satisfactory for leading them to concentrated thinking about the public health systems of which they were a part.

\subsection{Federal Egg Diagram}

Among other measures, institute staff during some years introduced the "egg" representation of a public health system for environmental health developed by the Centers for Disease Control and Prevention (Centers for Disease Control and Prevention, 2016). It is reproduced in Figure 1 below. It showed connections between some 24 kinds of organizations.

The egg diagram thus suggested potential relationships for the scholars to consider in thinking about a public health system. We believed it was a useful method for suggesting the broad scope of public health and the potential boundaries for the public health system. We suggested that each scholar consider which of the "eggs" might be an element in his or her immediate work responsibility. Their efforts to group the eggs to suit each scholar's particular area of responsibility-to identify the system boundaries-weren't very successful. Beyond that, the schematic didn't address relationships within the finer structures of the eggs. Determining the boundaries of a system, we concluded, is an art rather than a science and required careful consideration by each scholar (Midgley, 2006). However, these exercises did eventually suggest a method for

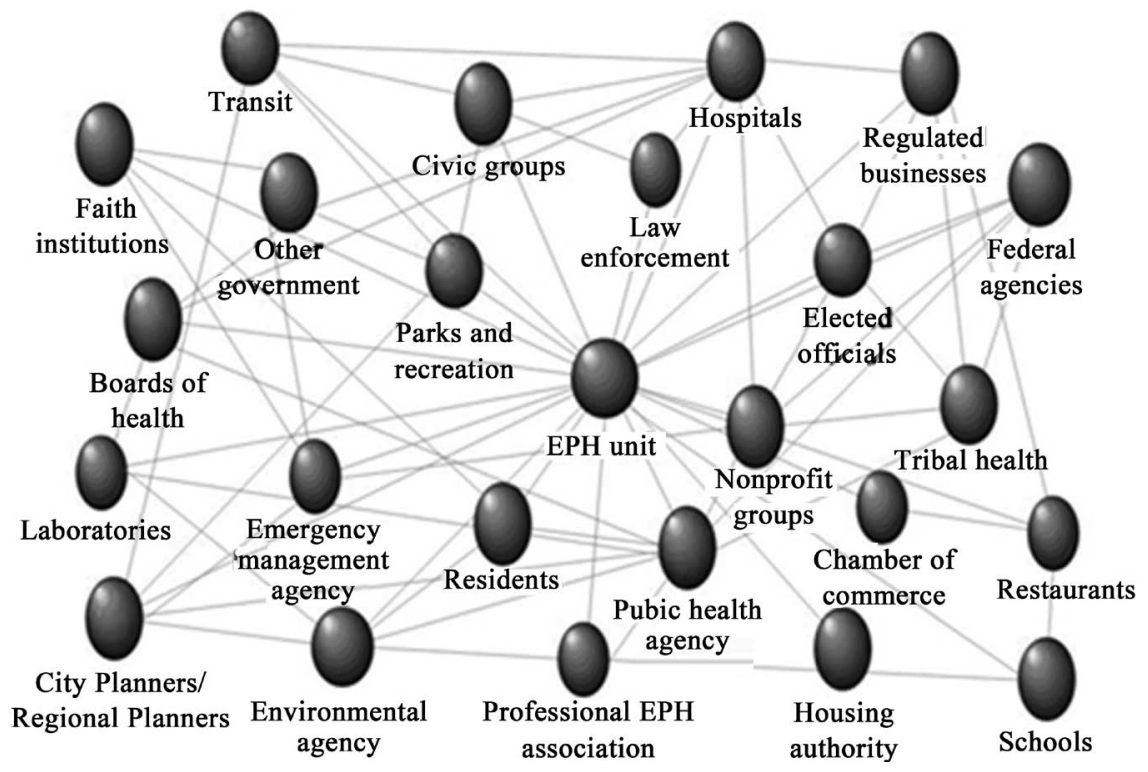

Source: http://www.cdc.gov/nceh/ehs/envphps/assessment_toolkit.htm.

Figure 1. Example of stakeholders in an environmental public health (EPH) system. 
our workshops and assignments.

The egg diagram portrayal of the public health system by CDC and other materials used in our training efforts raised additional questions about its boundaries for the scholars, beyond the formal bureaucratic structures and processes in which they worked.

\subsection{Boundary Definition Issues}

Questions related to defining a system's boundaries included:

- Each scholar had developed informal working relationships with colleagues in their agencies. Did those individuals become part of "their" public health system? What about colleagues in other county health departments, the units at the state level, or health departments in other states or at the federal level?

- Many were members of state or national professional associations. Did those associations, through such things as personal relationships, resources, and training become part of the official's public health system?

- Many were students in MPH or doctoral programs or had graduated from them and retained relationships with the university or individual instructors. Were these, too, part of the public health system of which the individuals were members?

- By virtue of the state's public health system, county health department directors worked with a variety of local government organizations, social service agencies, health care organizations, legislative delegations, and others. Were these parts of their systems?

The critical question for the scholars in this respect was: where were the scholars to draw the boundaries of "their" public health system?

\subsection{Did Major Practice Journals Publish Applications of Systems Thinking?}

In addition to materials which might help the scholars understand or think about systems, institute staff searched for examples of successful applications of systems thinking to the practice of public health. We reasoned that if such studies were published, they would likely be found in the two preeminent public health practice journals: The Journal of Public Health Management and Practice and Public Health Reports. Accordingly, institute staff and I searched each of these journals from their first issue to 2008 for helpful applications of systems thinking in practice. Unfortunately, we could find only one article that employed a form of systems thinking (Senge's disciplines and archetypes) in a study of a university program (Anderson, 2008). Other than this, we could find no useful guidance on how a public health official might think practically about his or her unique system. Generally, treatments of systems thinking (or systems analysis or systems theory) fell into a category of good to do (Lenaway et al., 2006) or abstract descriptions of elements of a public health system such as the NPHPSP 
noted above. In preparing this manuscript, the lead author invited a research librarian, now the second author, to review the earlier literature searches, to continue the literature searches through the last issues of 2019, and to contribute to writing and editing this article. Again, we found no other examples of applications of systems thinking in practice. The newer articles were generally similar to those found in our search a decade earlier. The lack of finding practice applications in both of the searches supported Green's (2006) findings and concerns.

\section{Difficulties in Application}

\subsection{Limitations on Institute Participants}

One of the drawbacks in applying systems thinking for the institute scholars was that their scope of authority was limited and many of the systems thinking materials seemed to be aimed at higher level officials who dealt with larger systems than those of our participants. Similarly, the consequences of systems thinking often called for activities and resources beyond the authority or reach of our participants, such as forming groups to define the boundaries of a system (group model building), creating community task forces as in MAPP (Salem, 2005), entering formal agreements with other units within the health department, with other agencies of state government, or with private organizations, deploying staff to engage in systems-related activities (e.g., implementing Senge's disciplines).

\subsection{Definitional Issues}

I and the Institute staff encountered additional problems with our efforts. For example, the system archetypes of Senge were difficult to understand and operationalize beyond simple examples offered by our workshop faculty. The terminology proved confusing in the readings-what was the difference between systems thinking, systems analysis, and systems theory? How did systems dynamics fit into the systems paradigm? What, indeed, was a public health system? Our assignment of several of the articles in an issue of the American Journal of Public Health (2006) on these topics didn't clarify things for the scholars (e.g., using methods beyond their resources, how to define the boundaries of a system effectively). We seemed to be encountering the twin problems of "turtles (systems) all the way down" and the sorites paradox. The problem of finding each entity thought of as a system entailing numerous (almost infinite?) subsystems and at what point does a system become a system or cease to become a system?

\subsection{Creation of a Personal Framework for Systems Thinking}

Given the difficulties the Institute's participants had with the approaches the Institute staff chose, we decided to abandon some of the earlier methods for presenting and explaining systems thinking. We continued to believe that systems thinking could be valuable for public health officials for viewing the array of contributing elements in public health and in participating in the common language of public health. We concluded that construction of an individual-centered 
framework might be the most fruitful approach, one that was in some ways similar to environmental scanning in strategic planning (Reid, Barnette, \& Mahan, 1998). Institute staff introduced the outline of this way of thinking about systems thinking to our last class of scholars who reported that it was going to be helpful to them and subsequent classes. They made a number of improving suggestions, but the institute ended before we could further develop our methods.

\section{The Expanded Personal Systems Thinking Framework}

We describe below an expanded version of the framework based on the foundation in 2008-2009 that shows what we believe to be a realistic and practical approach to systems thinking.

\subsection{Critical Aspects of the Framework}

As we noted earlier, there were several points that we found important for applying systems thinking. First, each scholar's public health system will be unique and personal-based on such things as his or her place in a bureaucracy, the scope of responsibilities, and established relationships inside and outside his or her agency or unit. Second, communication was essential in the identification of the individual official's public health system. The social scientist observer or public health researcher might look for regularities in processes among or within agencies or gross measures for comparison purposes (finance, organizational structure, services provided) but these will tell the public health worker little about his or her personal system and will reveal little about the extent or quality of the relationships among that system's elements. Although (as the egg diagram suggests), there are many elements that can exist in a public health system, their existence in itself does not mean there is a system in place.

\subsection{Importance of Personal Relationships}

There must be established and understood relationships among some of the individuals who are members of the eggs. A critical question then for scholars is "do you have that kind of relationship?" Because schools provide health education does not mean they are part of a system with the public health agency. Their work may be directed toward common ends but without communication and coordination to some degree, they are not members of a system. We believe for a system to be said to exist and for someone to be said to be a member of that system that it is essential for there to mutually understand that they are members of the system (Winch, 1958: pp. 46-48).

\subsection{Conflict and Competition Always Present}

Further, we found that much of the research and writing on systems and systems thinking in public health did not address common features of organizations: competition and conflict. In this neglect, students of public health and managers in public health agencies are similar to other social scientists and bureaucrats 
(MacIntyre, 1998: pp. 66-67; Block, 1990). These are ever present, commonly experienced, and yet rarely addressed as a public health organizational issue to be considered as part of systems thinking.

\section{The Expanded Framework Requires Addressing Critical Questions}

\subsection{Questions Related to the Managers Themselves}

Institute staff asked each scholar to begin with an inventory of his or her thinking about several questions related to their leadership.

These included:

1) What are your personal goals in your current position?

2) How will you define your success for those goals (e.g., better leadership, greater efficiency, effectiveness, influence, advancement)?

3) What are the boundaries of your personal public health system?

4) What changes in those boundaries will increase your success in reaching your goals?

As noted above, there were significant constraints on middle managers. So, how might the middle manager approach systems thinking from a personal perspective. Our model called for consideration of several dimensions that are personal in nature, as illustrated by Figure 2 below and which focus on questions 3 and 4 above.

\subsection{Middle Managers Are Truly in the Middle of Their Systems}

"You" is the middle manager identifying his or her system. The model, shown in Figure 2 below, requires that the manager have some existing communications and relationships with the other elements of the model. We asked the scholars to flesh out their systems through a series of representative questions (others could be added as needed).

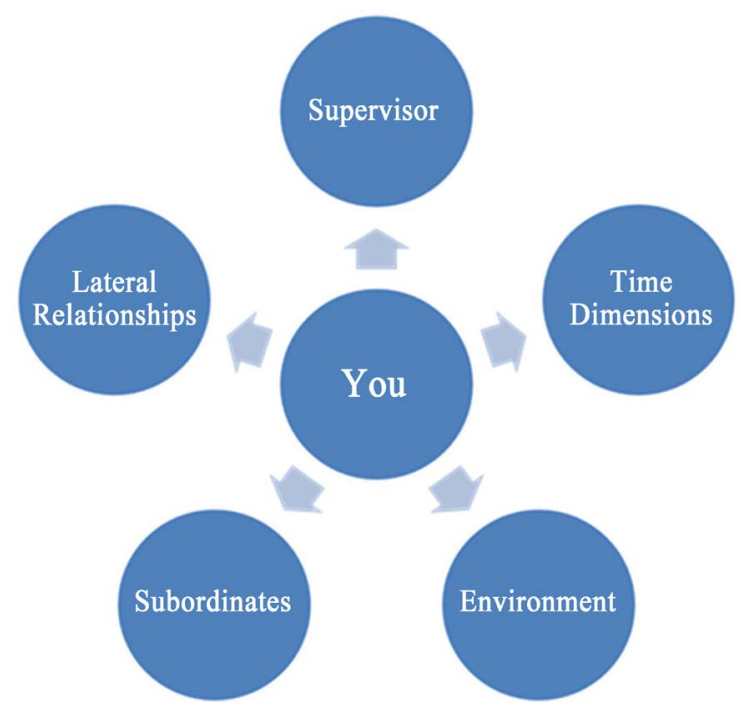

Figure 2. The CDC public health system diagram. 
The results would be a description of the boundaries of the manager's system, a structured assessment of the manager's relationships within that system, an identification of areas for enhancement of that system, and changes that would advance one's leadership goals.

\subsection{The Questions We Proposed Were}

\subsubsection{Relations with Supervisor}

Do you know your supervisor's personal goals?

What agreements (informal and formal) do you have with supervisor?

What are your personal relationships with your supervisor (how much mutual trust is there)?

What resources are available from supervisor if you wish to create a new personal system?

\subsubsection{Relations with Lateral Officials}

What policies and regulations affect these relations? (You are in a Weberian bureaucracy).

What agreements do you have with them (informal and formal)?

What resources do you both have that might be used to potentiate those agreements?

What are your personal relations with them (are they trustworthy, competitors)?

Are there opportunities for greater collaboration (e.g., incorporating them into "your" new system)?

\subsubsection{Relations with Subordinates}

What are the skills and deficits of the personnel who report to you?

Are they, or can they be, valuable contributors to your personal system?

What are their work and personal goals?

What are your relations with them, especially with respect to mutual trust?

When you have defined "your" system, can you safely explain it to them so that they see it as important to them as well as you?

\subsubsection{The Time Dimension}

What is the history of your unit?

What is its reputation?

What have you done to lead to the present situation?

What processes or developments may affect your work in the future (see environment questions)?

How can I use my relationships, resources, and personality to influence the future of my "new" system and reach my personal goals?

\subsubsection{Environment Questions}

What is occurring within the larger organization that could affect me. Can I do anything to protect or enhance "my system"? 
Are there policy changes coming from outside my organization that will affect my system (e.g., legislature, governor, U.S. Congress)?

What are my professional memberships, personal relations with colleagues in my state and outside it, personal relations with influentials (e.g., local legislators) and members of other community, state, or national organizations? How can I enhance them? How can these be helpful in creating my "new system" and reaching my goals?

\section{Discussion}

The result of the above exercise will be a first approximation of defining the middle manager's system and its boundaries. The answers to the questions will identify current relationships, areas of conflict or competition (lack of trust, goals of others), and areas for adjusting the personal system boundaries. It can also suggest areas where the manager's efforts at gaining resources, identifying obstacles, or forming relationships can aid in achieving personal and organizational goals.

This personal approach to systems thinking has other advantages. It can provide a means for meeting the widespread identified need for systems thinking improvement and training. In a time of constrained budgets, it is almost cost-free. There is no need for consultants, workshops, or extensive time commitments. Further, it is scalable. It could be used by the individual manager, by the manager with trusted colleagues or staff, or as part of low-cost workshop with other interested officials who are part of or who might become part of the manager's system. It has no time constraint on its completion. As we conceived of it, it will always to some degree be a work in progress, with resources, allies, opponents, obstacles, and opportunities changing over time. Finally, and perhaps critically, it requires no formal approval by a supervisor. It may be done privately when the middle manager finds the need and opportunity. We believe this approach will overcome many practical and conceptual difficulties that we found associated with other approaches to systems thinking.

\section{Conclusion}

As public health organizations and others confront ordinary and grave challenges (such as the coronavirus pandemic) with often reduced funding, fewer resources will be available for training. Research has found a consistent and enduring need for training in systems thinking. The method described in this paper will allow individual managers to conduct their personal systems thinking and create the basis for their strategies to carry out their personal goals and those of their organization.

\section{Conflicts of Interest}

The authors declare no conflicts of interest regarding the publication of this paper. 


\section{References}

American Journal of Public Health (2006). Vol. 96, Number 3 (Entire Issue).

Anderson, A. L. (2008). University Environmental Health Program Recruitment and Stability: A Systems Analysis. Journal of Public Health Management and Practice, 14, 51-55. https://doi.org/10.1097/01.PHH.0000303413.19851.17

Angeloni, M., Bialek, R., Petros, M. P., \& Fagen, M. C. (2019). Prioritizing Workforce Development Training in State Health Departments Using TRAIN: Challenges and Opportunities. Public Health Reports, 134, 172-179. https://doi.org/10.1177/0033354919826564

Aristotle (1962). The Politics of Aristotle. Edited and Translated by Ernest Barker, New York: Oxford University Press.

Block, P. (1990). The Empowered Manager: Positive Political Skills at Work. San Francisco, CA: Jossey-Bass.

Brunton, C. T., \& Smedley, B. D. (2019). Building Public Health Capacity to Advance Equity. Journal of Public Health Management and Practice, 25, 411-412. https://doi.org/10.1097/PHH.0000000000001040

Centers for Disease Control and Prevention (2016). Examples of Stakeholders in an Environmental Public Health (EPH) System.

http://www.cdc.gov/nceh/ehs/envphps/assessment_toolkit.htm

Green, L. W. (2006). Public Health Asks of Systems Science: To Advance Our Evidence-Based Practice, Can You Help Us Get More Practice-Based Evidence? American Journal of Public Health, 96, 406-409. https://doi.org/10.2105/AJPH.2005.066035

Hoehner, C. M., Sabounchi, N. S., Brennan, L. K., Hovmand, P., \& Kemner, A. (2015). Behavior-over-Time Graphs: Assessing Perceived Trends in Healthy Eating and Active Living Environments and Behaviors across 49 Communities. Journal of Public Health Management and Practice, 21, S45-S54. https://doi.org/10.1097/PHH.0000000000000211

Institute of Medicine (1988). The Future of Public Health. Washington DC: National Academy Press.

Lammers, J. C., \& Vandna, P. (1997). Applying Systems Thinking to Public Health Leadership. Journal of Public Health Management and Practice, 3, 39-49. https://doi.org/10.1097/00124784-199707000-00009

Lenaway, D., Halverson, P., Sotnikov, S., Tilson, H., Corso, L., \& Millington, W. (2006). Public Health Systems Research: Setting a National Agenda. American Journal of Public Health, 96, 410-413. https://doi.org/10.2105/AJPH.2004.046037

MacIntyre, A. C. (1998). The MacIntyre Reader. Notre Dame, IN: University of Notre Dame Press.

Mays, G. P., Halverson, P. K., \& Scutchfield, F. D. (2003). Behind the Curve? What We Know and Need to Learn from Public Health Systems Research. Journal of Public Health Management and Practice, 9, 179-182. https://doi.org/10.1097/00124784-200305000-00001

Meyer, A.-M., Davis, M., \& Mays, G. P. (2012). Defining Organizational Capacity for Public Health Services and Systems Research. Journal of Public Health Management and Practice, 18, 535-544. https://doi.org/10.1097/PHH.0b013e31825ce928

Midgley, G. (2006). Systemic Intervention for Public Health. American Journal of Public Health, 96, 466-472. https://doi.org/10.2105/AJPH.2005.067660

Reid, W. M., \& Dold, C. J. (2016). Leadership Training and the Problems of Competency 
Development. Journal of Public Health Management and Practice, 23, 73-80. https://doi.org/10.1097/PHH.0000000000000456

Reid, W. M., Barnette, D., \& Mahan, C. (1998). Local Health Departments: Planning for a Changed Role in the New Health Care Environment. Journal of Public Health Management and Practice, 4, 1-12. https://doi.org/10.1097/00124784-199809000-00003

Salem, E. (2005). The Promise of MAPP: A Transformational Tool for Public Health Practice. Journal of Public Health Management and Practice, 11, 379-380. https://doi.org/10.1097/00124784-200509000-00001

Senge, P. M. (1990). The Fifth Discipline: The Art and Practice of the Learning Organization. New York: Doubleday/Currency.

Senge, P. M., Kleiner, A., Roberts, C., Ross, R. B., \& Smith, B. J. (1994). The Fifth Discipline Field Book: Strategies and Tools for Building a Learning Organization. New York: Doubleday.

Williams, J. C. (2015). A Systems Thinking Approach to Analysis of the Patient Protection and Affordable Care Act. Journal of Public Health Management and Practice, 21, 6-11. https://doi.org/10.1097/PHH.0000000000000150

Winch, P. (1958). The Idea of a Social Science and Its Relation to Philosophy. London: Routledge \& Kegan Paul.

Winslow, C. E. A. (1920). The Untilled Fields of Public Health. Science, 51, 23-33. https://doi.org/10.1126/science.51.1306.23

Wright, K., Rowitz, L., Merkle, A. et al. (2000). Competency Development in Public Health Leadership. American Journal of Public Health, 90, 1202-1207.

https://doi.org/10.2105/AJPH.90.8.1202 